16.7-02 AN X-RAY HIGH TEMPERATURE CAMERA. BY W. Adlhart, E. Jagodzinslsi, S. Sueno and N. Tzafaras, Institut fur Tristallographie und Minexalogie der Universität Müchen, Minchen, Federal Republic of Germany.

A heating camera has been developed for film and counter investigations of single crystals for a temperature range of 300 to $1900 \mathrm{~K}$. Furthermore it is possible to apply various gas partial pressures. The oxygen partial pressure can be varied between $10^{-8}$ to $10^{-1}$ mbar in the temperature range of 500 to $1100 \mathrm{~K}$. The camera is designed for the use of focussing monochromators. Various focussing conditions may be achieved by either turning around ox translating along the incident beam (H. Jagodzinski, Acta Cryst. (1968) B24, 19). Since modified Weissenberg cameras are used,also Weissenberg oscillations and Noromosic techniques (H. Jagodzinski and M. Korekawa, Geochim. Cosmochim. Acta Suppl. 4 (1975) Vol. 1, 955) can be performed. The camera consists mainly of a Be-tube (diameter $=57.3 \mathrm{~mm}$, length $=110 \mathrm{~mm}$, wall thichness $=0.5 \mathrm{~mm}$ ), a tubular graphite heating element and a $P t-P t$, Rh thermocouple at the distance of 1 mu from the crystal. Depending on the precision of the gauging, a PID controllex provides an absolute accuracy of $5-10 \mathrm{k}$, a stabilization of $0.2 \mathrm{~K}($ at $400 \mathrm{~F})$ and a reproducibility of $1-2 \mathrm{~K}($ at $1350 \mathrm{~K})$. The heating power is $250 \mathrm{~W}$ at $\mathrm{T}=1900 \mathrm{~K}$.
16.8-01 APPIICATION OF SYTTHESIZED HOLOGRAMS TO ELECTRON-MICROSCOPIC STUDIES OF CRYSTAIS. By V.V.Aristov, G.A.Bashkina, A.I.Erko, I.S. Kohanchick, I.I.Khodos, Institute of Solid State Physics, Academy of Sciences of the USSR, Chernogolovka, Moscow district, 142432 , USSR?

The paper investigates the applicability of holograms synthesized in respect to projections, obtained in EN to the measurements of various geometrical parameters of crystals. The messured parameters in TEM are the following: directions of dislocation lines, depth of defects occurence and in SEM - relief of the surface. Relative accuracy of measurements may be as great as I-0, I\%。

The investigations performed show that the synthesized holograms (SH) look promising for getting information on the value of local electric and magnetic fields at the specimen surface. The messurements can be carried out over the pseudorelief of the gurface arising on reconstruction of the $\mathrm{SH}$.
16.7 003 FIGH TEMPERATURE DIAMOND AITIL CELI FOR SINGIE CRYSTAI X-RAY EYPERINENTS. BY S. Miyano and S. Sueno, Department of Geoscience, The University of Tsukuba, Ibarati, 305, Jepen.

A small diamond anvil cell with a small heater is usefull for high-temperature and high-pressure single crystal X-ray experiments, especially for the in-situ observation of phase transition and recrystalization phenomena. We have designed a dianond cell $32 \mathrm{~mm}$ in diameter, $12 \mathrm{~mm}$ in thickness and $70 \mathrm{~g}$ on weight, and tried to install several types of heater on it. A band type heater surrounding the outside of the cell showed the best results. The size of the cell with the heater is about $50 \mathrm{~mm}$ in diameter, $30 \mathrm{~mm}$ in thickness and $170 \mathrm{~s}$ on weight. The maximum temperature so far we have obtained is $550^{\circ} \mathrm{C}(100 \mathrm{~V}-100 \mathrm{~W})$. The whole system can be mounted on a nomal goniometer-head and it is easy to take single crystal photographs on the standard type precession camera with a slifht modification at the collimator and beam-stopper. One difficulty on the high-temperature and high-pressure work of the diamond cell is the pressure decrease at higher ternperature, especially above $470^{\circ} \mathrm{C}$. This may mainly be caused by the leaking of liquid pressure medium by the distortion or softening of the metal gasket. NaCl powder as pressure medium showed better results. This system is also very convenient for the in-situ observation of transition or recrystallization phenomena on the standard polarizing microscope with e small water cooling cover for protecting the objective lens from heat. The temperature of the specimen can be measured by thermo-couple attached by the diamond anvil. The pressure measurement at high temperature is difficult because the convenient ruby $R$ l line shift method can not be applied above $400^{\circ} \mathrm{C}$ due to broadening of the $R_{1}$-peak.

\section{8-02 Light SCATTERING TOMOgRAPHY}

FOR DETECTION OF CRYSTALLINE DEFECTS. By Kazuo Moriya and Tomoya Ogawa.

Dept. of Physics, Gakushuin Univ, Mejiro, Tokyo, Japan. Light scattering tomography was developed for the observations of clusters of hydrogen bonded $\mathrm{OH}$ caused by fluctuations in growth speed of synthetic quartz crystals (J. Cryst. Growth 44 (1987) 53), undecorated dislocation Iines (Phil. Mag. $\overline{41} \mathrm{~A}$ (1980) 191) and plate-like defects in the crystals (Phil. Mag. A, in press) which act as phase objects.

Each tomograph was taken by a single scanning of a light pencil with about $20 \mu \mathrm{m}$ diam from a few $\mathrm{mW}$ He-Ne laser using a streak camera and uItra-microscope shown schematically in

the figure. Layer-by-

layer tomographs obtained successively give a bird's eye view of defects in a crystal. The defects will be characterized by their image contrasts which are sharply dependent upon the scattering vector.

The results obtained in synthetic quartz \& diamond crystals will be presented. 